\title{
Quadros clínico-patológicos do envenenamento ofídico por Crotalus durissus terrificus e Bothrops spp. em animais de produção ${ }^{1}$
}

\author{
Carlos Hubinger Tokarnia2*, Marilene Farias Brito ${ }^{3}$, José Diomedes Barbosa ${ }^{4}$ \\ e Jürgen Döbereiner ${ }^{5}$
}

\begin{abstract}
Tokarnia C.H., Brito M.F., Barbosa J.D. \& Döbereiner J. 2014. [Clinical and pathological pictures of snakebite poisoning by Crotalus durissus terrificus and Bothrops spp. in livestock.]Quadros clínico-patológicos do envenenamento ofídico por Crotalus durissus terrificus e Bothrops spp. em animais de produção. Pesquisa Veterinária Brasileira 34(4):301312. Departamento de Nutrição Animal e Pastagem, Instituto de Zootecnia, Universidade Federal Rural do Rio de Janeiro, Seropédica, RJ 23890-000, Brazil. E-mail: tokarnia@ufrrj.br

A review was performed about the clinical and pathological pictures caused by the venoms of Crotalus durissus terrificus and Bothrops spp. in cattle, buffaloes, horses, sheep and swine. The data were compiled from experiments in livestock species found in the literature, from experimentation accomplished by our research group, and from communicated natural cases of snakebite poisoning. The most important data were placed on two Tables, the analysis of which revealed some interesting aspects: (1) in our experiments the venom of Crotalus durissus terrificus caused in horses severe edema at the site of subcutaneous injection, to the contrary as observed in all other experimental animal species, an aspect not recorded in the literature; (2) in our experiments the venom of Bothrops species in cattle, sheep and horses, injected subcutaneously, did not cause edema as generally reported in the literature, but caused severe subcutaneous hemorrhages at the injection site. In the non fatal cases the blood was reabsorbed in a few days without leaving sequelae; exception was the reaction to the venom of Bothrops jararacussu, which caused edema in the experimental sheep, and severe tumefaction resulting in fistulous elimination of serous liquid in the experimental horses. The aim of this study was to contribute for the diagnostic of snakebite accidents in livestock.
\end{abstract}

INDEX TERMS: Snake venom poisoning, Crotalus durissus terrificus, Bothrops spp., livestock.

RESUMO.- Foi realizada uma revisão dos quadros clínico-patológicos causados pelos venenos de Crotalus durissus terrificus e Bothrops spp. em bovinos, búfalos, ovinos equinos e suínos. Foram compilados os dados obtidos pela experimentação em animais de produção encontrados na

\footnotetext{
${ }^{1}$ Recebido em 12 de março de 2014.

Aceito para publicação em 16 de abril de 2014.

${ }^{2}$ Departamento de Nutrição Animal e Pastagem, Instituto de Zootecnia (IZ), Universidade Federal Rural do Rio de Janeiro (UFRRJ), Seropédica, RJ 23890-000, Brasil. *Autor para correspondência: tokarnia@ufrri.br

${ }^{3}$ Departamento de Epidemiologia e Saúde Pública, Instituto de Veterinária (IV), UFRRJ, Seropédica, RJ 23890-000, Brasil.

${ }^{4}$ Escola de Medicina Veterinária, Campus Castanhal da Universidade Federal do Pará (UFPA), Rua Maximino Porpino 1000, Castanhal, PA 68740080, Brasil. E-mail: diomedes@ufpa.br

${ }^{5}$ Projeto Sanidade Animal, Convênio Embrapa/UFRRJ, Seropédica, RJ 23851-970, Brasil.
}

literatura e os obtidos através de experimentação realizada por nossa equipe. Também foram revisados os casos naturais de envenenamento ofídico comunicados. Em dois Quadros foram lançados os mais importantes dados dessas revisões, que revelou diversos aspectos interessantes: 1) em nossos experimentos, o veneno de Crotalus durissus terrificus, quando injetado por via subcutânea em cavalos, causou um edema acentuado no local da aplicação, ao contrário do que tem sido observado em todas as outras espécies animais, aspecto não relatado na literatura; 2) em nossos experimentos, o veneno de diversas espécies de Bothrops, quando injetado por via subcutânea em bovinos, ovinos e equinos, não causou edema como em geral é relatado na literatura, e sim hemorragias subcutâneas acentuadas no local da aplicação. Nos casos não fatais este sangue era reabsorvido em poucos dias sem deixar sequelas. Exceção foi a reação ao veneno de Bothrops jararacussu, que causou 
edema nos ovinos experimentais, e tumefação acentuada que resultou em fístula com eliminação de líquido seroso nos equinos experimentais. 0 objetivo do presente estudo visa contribuir para o aperfeiçoamento do diagnóstico de acidentes ofídicos em animais de produção.

TERMOS DE INDEXAÇÃO: Envenenamento ofídico, Crotalus durissus terrificus, Bothrops spp., animais de produção.

\section{INTRODUÇÃO}

A análise dos dados do quadro clínico-patológico, na maioria das doenças, é o procedimento mais importante no estabelecimento do diagnóstico.

Em relação à ação e ao quadro clínico-patológico que as toxinas ofídicas provocam, há no Brasil, muitos dados, na sua maioria, baseados em envenenamento no homem e em experimentos realizados em animais de laboratório. Apesar de a maioria desses estudos valerem também para animais de produção, é necessário alertar que há diferenças; segundo Amorim et al. (1951) os sinais clínicos e as lesões, além de variarem com o gênero e a espécie da serpente envolvida no acidente, também diferem em função da espécie animal-vítima.

De fato, foram realizados muitos experimentos com venenos ofídicos em animais de produção, mas com a principal finalidade de estudar a sensibilidade das diversas espécies animais aos venenos ofídicos e sobre a elaboração e uso de soros antiofídicos. Nesses trabalhos há poucos dados sobre o quadro clínico-patológico que os diferentes venenos ofídicos causam.

Com o objetivo de contribuir para o aperfeiçoamento do diagnóstico de acidentes ofídicos em animais de produção, realizamos uma revisão dos dados da literatura e dos obtidos através de experimentos feitos por nossa equipe com os venenos de alguns ofídios em diferentes espécies de animais de produção.

\section{METODOLOGIA}

Nesta revisão procedemos da seguinte maneira:

1) Compilamos os dados obtidos pela experimentação em animais de produção encontrados na literatura e os obtidos atra- vés da experimentação realizada por nossa equipe. Os dados são agrupados (a) de acordo com o ofídio (Crotalus durissus terrificus ou Bothrops spp.), e (b) de acordo com a espécie animal-vítima.

2) Revimos os dados de casos naturais de envenenamento ofídico relatados, cujo diagnóstico foi estabelecido com razoável segurança.

3) Fizemos uma comparação, em relação (a) às diferenças no quadro clínico-patológico verificado através da experimentação em animais de produção, dos dados encontrados na literatura com os verificados por nossa equipe, e (b), por outro lado, comparamos as diferenças no quadro clínico-patológico, verificadas no homem e o observado através de experimentos em animais de laboratório (descrições gerais) com os verificados nos experimentos encontrados na literatura em animais de produção e os verificados por nossa equipe.

\section{RESULTADOS}

\section{Quadro clínico-patológico do envenenamento experi- mental crotálico (Quadro 1)}

\section{Dados da literatura referentes a bovinos}

Em trabalho experimental, realizado por Araujo \& Belluomini (1960/1962), cujas observações relativas ao quadro clínico-patológico se restringem à constatação de haver ou não edema e/ou necrose no local da aplicação do veneno ofídico, com a inoculação intramuscular do veneno de Crotalus durissus terrificus em bovinos, os autores relatam que não houve formação de edema ou necrose em bovinos.

Em experimentos realizados em bovinos por Araujo et al. (1963a ), cujas observações relativas ao quadro clínico-patológico também se restringem à constatação de haver ou não edema e/ou necrose no local da aplicação do veneno ofídico, igualmente não verificaram edema ou necrose no local da aplicação do veneno crotálico pela via intramuscular (bordo posterior da coxa) ou subcutânea (bochecha).

Em 92 bovinos que receberam, por via intramuscular, uma mistura de venenos de Crotalus durissus terrificus e Crotalus durissus collilineatus, e depois foram tratados com soro antiofídico específico, Belluomini et al. (1982) obser-

Quadro 1. Achados clínicos e de necropsia no envenenamento pelas toxinas de Crotalus durissus terrificus

\begin{tabular}{|c|c|c|c|c|c|c|c|c|c|}
\hline \multicolumn{5}{|c|}{ Dados da literatura } & \multicolumn{5}{|c|}{ Dados dos nossos experimentos } \\
\hline & \multicolumn{2}{|c|}{ Edema } & \multicolumn{2}{|c|}{ Necrose } & & \multicolumn{2}{|c|}{ Edema } & \multicolumn{2}{|c|}{ Necrose } \\
\hline & SC & IM & $\mathrm{SC}$ & IM & & SC & IM & SC & IM \\
\hline Bovinos & & & & & Bovinos & & & & \\
\hline Araujo \& Belluomini 1960/1962 & NR & A & NR & A & Graça et al. 2008 & A & NR & A & NR \\
\hline Araujo et al. $1963 a$ & A & A & $\mathrm{A}$ & A & & & & & \\
\hline Búfalos & & & & & Búfalos & & & & \\
\hline Sem referências & NR & NR & NR & NR & Barbosa et al. 2008 & A & NR & $\mathrm{A}$ & NR \\
\hline Ovinos & & & & & Ovinos & & & & \\
\hline Araujo \& Belluomini 1960/1962 & NR & $\mathrm{A}$ & NR & A & Sem referências & NR & NR & NR & NR \\
\hline Equinos & & & & & Equinos & & & & \\
\hline Araujo \& Belluomini 1960/1962 & NR & $\mathrm{P}+$ & NR & A & Lopes et al. 2012 & $\mathrm{P}+++$ & NR & A & NR \\
\hline Suínos & & & & & Suínos & & & & \\
\hline Araujo \& Belluomini 1960/1962 & NR & A & NR & A & Sem referências & NR & NR & NR & NR \\
\hline Araujo et al. $1963 \mathrm{~b}$ & A & $\mathrm{P}+$ & A & A & & & & & \\
\hline
\end{tabular}

$\overline{\mathrm{SC}}=$ subcutâneo, $\mathrm{IM}=$ intramuscular, $\mathrm{NR}=$ não realizado, $\mathrm{A}=$ ausência de edema ou necrose, $\mathrm{P}=$ presença de edema ou necrose. + Lesão leve, +++ lesão acentuada. 
varam, 2-6 horas após a aplicação do veneno, dificuldades de locomoção e de ficar em estação, permanência em decúbito lateral, abolição do reflexo palpebral, sem ptose, abolição do reflexo pupilar fotomotor, paralisia motora reversível do globo ocular entre 6 e 72 horas, ausência de hemoglobina e de outras alterações macroscópicas da urina ou da micção; verificaram ainda sinais clínicos interpretados como secundários, entre eles apatia, sialorreia, anorexia, sede, paresia do rúmen e timpanismo agudo.

Pelas análises da urina de 15 bovinos que, ao que tudo indica, receberam os mesmos venenos acima citados (dos quais 10 foram tratados com soro antiofídico específico e 5 não receberam tratamento; morreram os 5 animais não tratados e mais 7 dos tratados, em 7-156 horas após a aplicação do veneno), Birgel et al. (1983) concluíram que esse veneno causa lesão progressiva do néfron com diminuição de capacidade de reabsorção de substâncias à altura dos túbulos contornados proximais, seguida de proteinúria, glicosúria e concentração urinária diminuída (sic). Em $60 \%$ dos casos havia microhematúria, congestão renal e maior permeabilidade dos glomérulos renais. Esses achados indicariam uma glomerulonefrite. Apesar da administração de doses letais, não se conseguiu demonstrar efeito hemolítico e consequente hemoglobinúria. Os autores ainda afirmaram que, através do exame de urina, seria fácil em bovinos diferenciar o envenenamento crotálico (sem hematúria e sem hemorragias) do produzido por jararacas (hematúria e hemorragias extensas) e intoxicação por plantas que causam hemoglobinúria.

Através de estudos anátomo-histopatológicos realizados por Saliba et al. (1983) em 16 bovinos (que, ao que tudo indica, fizeram parte do estudo de Belluomini et al. 1982 acima mencionado), aos quais foram aplicados os mesmos venenos crotálicos acima citados (todos os 12 tratados com soro específico, bem como os quatro não tratados, morreram), relataram as seguintes lesões macroscópicas: petéquias em todos os órgãos e congestão em serosas e mucosas, mais presentes no sistema nervoso central, onde, ocasionalmente, também foram observadas extensas hemorragias subdurais. No local da injeção do veneno mencionaram uma inflamação seroso-purulenta (sic) da pele e do tecido subcutâneo, que clinicamente não foi possível reconhecer. Ao exame microscópico, observaram numerosas hemorragias subdurais e acúmulo de sangue nos espaços perivasculares no sistema nervoso central. Em 43\% dos bovinos descreveram necrose hialina nas paredes das arteríolas no sistema nervoso central, no pulmão e no local da aplicação do veneno, e em $31 \%$ dos casos trombos hialinos na luz de arteríolas e capilares pulmonares. No rim havia processos degenerativos, inclusive degeneração hidrópica culminando em necrose tubular e presença de albumina no espaço intracapsular (sic). Na luz dos túbulos não se observaram cilindros hialinos ou de hemoglobina, porém, em $31 \%$ dos animais, havia glomerulonefrite focal. No miocárdio havia degeneração vacuolar.

Através da inoculação intramuscular do veneno de Crotalus durissus terrificus em cinco bovinos com 2-3 anos, Lago (1996) observou severo quadro neurológico, caracterizado por apatia, letargia profunda, mioclonias, diminui- ção do tônus muscular, diminuição de reflexos superficiais, incoordenação motora, decúbito lateral, movimentos de pedalagem, perda de sensibilidade à dor profunda, paralisia flácida, dispneia e morte entre $20 \mathrm{~h} 42 \mathrm{~min}$ e $39 \mathrm{~h} 24 \mathrm{~min}$ após a inoculação. Pequeno edema transitório foi observado no local da inoculação. Houve aumento do tempo de coagulação sanguínea, leucocitose, hipofibrinogenemia e aumento da concentração sérica de ureia e de creatinafosfoquinase. As alterações anátomo-histológicas consistiram em leves hemorragias nos pulmões, intestinos, músculos, e em maior intensidade, no coração. Nos músculos esqueléticos e cardíaco havia degeneração hialina, vacúolos e infiltrados celulares.

\section{Dados da nossa equipe referentes a bovinos}

Graça et al. (2008) em experimentos com a inoculação do veneno de Crotalus durissus terrificus, por via subcutânea em oito bovinos, verificaram que o bovino que recebeu a dose de $0,03 \mathrm{mg} / \mathrm{kg}$, morreu. A dose de 0,015 causou a morte em quatro dos sete bovinos inoculados, enquanto que os dois bovinos que receberam $0,0075 \mathrm{mg} / \mathrm{kg}$ adoeceram discretamente. Nos animais que receberam doses potencialmente letais $(0,03$ e $0,015 \mathrm{mg} / \mathrm{kg})$, as primeiras alterações de comportamento foram evidenciadas a partir de $1 \mathrm{~h} 30 \mathrm{~min}$. A evolução oscilou entre $5 \mathrm{~h} 25 \mathrm{~min}$ e $45 \mathrm{~h}$ nos animais que morreram, e entre $33 \mathrm{~h} 15 \mathrm{~min}$ e 17 dias nos animais que se recuperaram. Os principais sinais nervosos observados foram diminuição da resposta aos estímulos externos e dos reflexos hipotônicos, arrastar dos cascos no solo, aparente apatia, paralisia do globo ocular e da língua, decúbito esternal e lateral. Verificaram-se também adipsia e, por vezes, petéquias nas mucosas vaginal e conjuntival. Exames complementares revelaram discreto a moderado aumento do tempo de sangramento e moderado aumento do tempo de tromboplastina parcial ativada. Houve moderada leucocitose com neutrofilia, linfopenia relativa, eosinopenia, monocitose e discreto aumento do número de bastões. Foi evidenciado significativo aumento dos níveis séricos de creatinaquinase, contudo, não foram observadas alterações significativas através da urinálise. À necropsia constataram-se edema quase imperceptível no local da inoculação, discretas petéquias e sufusões no epicárdio, omento, vesícula biliar e mucosa da bexiga, em alguns dos animais envenenados experimentalmente. Os exames histopatológicos revelaram necrose (hialinização) de grupos de miócitos ou em miócitos isolados em dez diferentes músculos esqueléticos examinados, próximos ou distantes do local de inoculação em todos os animais necropsiados. Concluiu-se que o envenenamento por Crotalus sul-americanas em bovinos não cursa com mioglobinúria e que o quadro de paralisia flácida mimetiza o observado no botulismo.

\section{Dados da nossa equipe referentes a búfalos e bovinos}

Barbosa et al. (2011) ao realizarem um estudo comparativo da sensibilidade ao veneno de Crotalus durissus terrificus entre búfalos e bovinos, inocularam por via subcutânea em três búfalos doses de 0,015, 0,03 e 0,066mg/ $\mathrm{kg}$, e em dois bovinos doses de 0,03 e $0,066 \mathrm{mg} / \mathrm{kg}$. 0 buba- 
lino que recebeu a dose de $0,03 \mathrm{mg} / \mathrm{kg}$ apresentou sinais clínicos graves e recuperou-se, e o bovino que recebeu a mesma dose morreu com evolução de $22 \mathrm{~h} 56 \mathrm{~min}$. A dose de $0,066 \mathrm{mg} / \mathrm{kg}$ causou a morte tanto do bovino quanto do bubalino, com evolução clínica de 4h23min e $8 \mathrm{~h} 12 \mathrm{~min}$, respectivamente. 0 bubalino que recebeu a dose de $0,015 \mathrm{mg} /$ kg adoeceu levemente (evolução de 48 horas) e recuperou-se 72 horas após a inoculação do veneno. Os sinais clínicos tiveram início 3h58min no bubalino que morreu, e nos bubalinos que adoeceram, mas se recuperaram, dentro de $17 \mathrm{~h} 25 \mathrm{~min}$ e $24 \mathrm{~h} 00 \mathrm{~min}$ após a inoculação do veneno. Nos dois bovinos que morreram (doses 0,03 e $0,066 \mathrm{mg} / \mathrm{kg}$ ), os primeiros sinais clínicos foram observados $6 \mathrm{~h} 10 \mathrm{~min}$ e 6h31min após a inoculação do veneno. A inoculação do veneno produziu nos búfalos e nos bovinos um quadro nervoso de paralisia flácida. Os principais sinais clínicos observados, tanto nos búfalos quanto nos bovinos, foram discreto aumento de volume no local da inoculação, dificuldade respiratória caracterizada por respiração predominantemente abdominal, apatia, sialorreia, dificuldade para levantar-se quando estimulados, evolução para decúbito esternal permanente, seguido de decúbito lateral, movimentos de pedalagem, e diminuição dos reflexos relacionados aos pares de nervos cranianos. Nos bubalinos adicionalmente foi observado aumento da base de sustentação, arrastar das pinças dos membros posteriores, marcha lenta e cambaleante e dificuldade na apreensão dos alimentos; nos bovinos ainda foram observados paralisia do globo ocular, revelada através da não exposição da esclera durante a rotação da cabeça na direção latero-caudal. Tanto nos bovinos quanto nos bubalinos, verificou-se no leucograma, leucocitose por neutrofilia, e na bioquímica sérica, aumento nos níveis de alanina aminotransferase, aspartato aminotransferase, creatinaquinase e deshidrogenase lática. Não houve alterações na urinálise, nem no tempo de ativação da protrombina e no tempo de tromboplastina parcial ativada. À necropsia evidenciou-se apenas discreto edema no local da inoculação em um bovino. Os achados histopatológicos observados foram picnose nos núcleos de células epiteliais de alguns túbulos uriníferos no córtex renal (em um búfalo e em um bovino) e vacuolização de hepatócitos (em um bovino).

\section{Dados da literatura referentes a ovinos}

Nos experimentos de Araujo \& Belluomini (1960/1962), os oito carneiros usados morreram em $3 \mathrm{~h} 30 \mathrm{~min}$ a 9 dias após a inoculação intramuscular dos venenos de Crotalus durissus terrificus; não foi observado edema ou necrose no membro injetado.

\section{Dados da literatura referente a equinos}

Em trabalho experimental com a inoculação intramuscular do veneno de Crotalus durissus terrificus, Araujo \& Belluomini (1960/1962) observaram formação de um pequeno edema no local da injeção e não houve necrose em nenhum cavalo.

\section{Dados da nossa equipe referentes a equinos}

No envenenamento experimental por Crotalus durissus terrificus realizado por Lopes et al. (2012) em cinco equi- nos, o veneno, inoculado por via subcutânea, causou a morte do equino que recebeu a dose de $0,12 \mathrm{mg} / \mathrm{kg}$ e de um dos dois que receberam a dose de $0,066 \mathrm{mg} / \mathrm{kg}$, com evolução de $27 \mathrm{~h} 27$ min e $52 \mathrm{~h} 29 \mathrm{~min}$, respectivamente. 0 segundo animal que recebeu a dose de $0,066 \mathrm{mg} / \mathrm{kg}$ também adoeceu, mas recuperou-se após 12 dias da inoculação. A dose de $0,03 \mathrm{mg} / \mathrm{kg}$ determinou, nos dois equinos, quadros não fatais do envenenamento, com período de evolução que variou entre 6 e 10 dias. 0 quadro clínico caracterizou-se por grande aumento de volume no local de inoculação (região escapular) que se estendeu por todo o membro, apatia e cabeça baixa, alterações locomotoras como arrastar das pinças no solo, decúbito e dificuldade para levantar, redução dos reflexos auricular, palatal, do lábio superior e de ameaça, e aumento das frequências cardíaca e respiratória. Os exames laboratoriais revelaram leucocitose por neutrofilia e linfocitose em apenas dois equinos. Houve aumento das enzimas creatinaquinase, deshidrogenase lática e da ureia, e também redução nos níveis séricos de cálcio, fósforo e magnésio. 0 tempo de tromboplastina parcial ativada aumentou nos equinos que morreram. Os achados de necropsia foram edema do tecido subcutâneo em todo o membro em que foi aplicado o veneno, sufusões no epicárdio dos ventrículos cardíacos esquerdo e direito, e bexiga com áreas hemorrágicas em grande parte da mucosa. Ao exame histopatológico observaram-se no fígado moderada vacuolização difusa, afetando mais a zona intermediária do lóbulo hepático, leve dilatação dos sinusoides hepáticos em algumas áreas, e rim com leve dilatação dos túbulos uriníferos, principalmente no córtex.

\section{Dados da literatura referentes a suínos}

Araujo et al. (1963b), em seus experimentos em porcos, verificaram que o veneno crotálico aplicado pela via intramuscular produziu pequeno edema. Pela via subcutânea (tecido adiposo) o veneno crotálico não ocasionou edema com as doses experimentadas. Não se observou necrose, tanto pela via intramuscular como pela subcutânea.

\section{Quadro clínico-patológico do envenenamento experi- mental botrópico (Quadro 2)}

\section{Dados da literatura referentes a bovinos}

Araujo \& Belluomini (1960/1962), em trabalho experimental da inoculação intramuscular, verificaram que os venenos B. jararaca, B. jararacussu, B. alternatus, B. cotiara, $B$. neuwiedi e B. atrox mostraram-se altamente ativos para formação de edema; causaram ainda necrose os venenos de $B$. jararacussu, B. neuwiedi e B. atrox. Os venenos de $B$. alternatus e $B$. cotiara não produziram necrose.

Em experimentos com bovinos, Araujo et al. (1963a) constataram que os venenos de Bothrops (as mesmas espécies acima mencionadas), independentemente da via de inoculação, das doses usadas e do local da aplicação, produziram acentuado edema em todos os bovinos. A formação de necrose foi observada somente com o emprego dos venenos botrópicos quando inoculados pela via intramuscular, com exceção do veneno de B. cotiara que não produziu necrose em nenhum animal injetado. Pela via subcutânea 
Quadro 2. Achados clínicos e de necropsia no envenenamento pelas toxinas de Bothrops spp.

\begin{tabular}{|c|c|c|c|c|c|c|c|c|c|c|c|c|}
\hline \multicolumn{6}{|c|}{ Dados da literatura } & \multicolumn{7}{|c|}{ Dados dos nossos experimentos } \\
\hline & Edema & \multicolumn{2}{|c|}{ Hemorragia } & \multicolumn{2}{|c|}{ Necrose } & & \multicolumn{2}{|c|}{ Edema } & \multicolumn{2}{|c|}{ Hemorragia } & \multicolumn{2}{|c|}{ Necrose } \\
\hline & SC IM & SC & IM & SC & $\mathrm{IM}$ & & SC & IM & SC & IM & $\mathrm{SC}$ & IM \\
\hline Bovinos & & & & & & Bovinos & & & & & & \\
\hline Araujo \& Belluomini 1960/1962 & NR $P$ & NR & A & NR & $\mathrm{P}^{\mathrm{a}}$ & Caldas et al. 2008 & A & A & $\mathrm{P}(+)$ & $\mathrm{A}$ & A & A \\
\hline Araujo et al. 1963a & $\mathrm{P} \quad \mathrm{P}$ & A & A & A & $\mathrm{P}^{\mathrm{b}}$ & & & & & & & \\
\hline Novaes et al. 1986 & $P$ NR & $\mathrm{P}$ & NR & A & NR & & & & & & & \\
\hline Búfalos & & & & & & Búfalos & & & & & & \\
\hline Sem referências & NR NR & NR & NR & NR & NR & Barbosa et al. 2011 & A & NR & $\mathrm{P}$ & NR & A & NR \\
\hline Ovinos & & & & & & Ovinos & & & & & & \\
\hline Araujo \& Belluomini 1960/1962 & NR P & NR & A & NR & A & $\begin{array}{l}\text { Diefenbach et al. } 2012 \\
\text { Aragão et al. } 2010\end{array}$ & A & NR & $P$ & NR & A & NR \\
\hline & & & & & & (B. jararaca) & A & NR & $\mathrm{P}$ & NR & A & NR \\
\hline & & & & & & (B. jararacussu) & $\mathrm{P}$ & NR & A & NR & A & NR \\
\hline Equinos & & & & & & Equinos & & & & & & \\
\hline Araujo \& Belluomini 1960/1962 & NR $P$ & A & A & A & A & $\begin{array}{l}\text { Souza et al. } 2011 \\
\text { (Bothrops spp.) }\end{array}$ & & & $\mathrm{P}$ & NR & A & NR \\
\hline & & & & & & (B. jararacussu) & P? & NR & A & NR & P? & NR \\
\hline Suínos & & & & & & Suínos & & & & & & \\
\hline Araujo \& Belluomini 1960/1962 & NR $P$ & NR & A & NR & A & Sem referências & NR & NR & NR & NR & NR & NR \\
\hline Araujo et al. 1963b & $\mathrm{P} \quad \mathrm{P}$ & A & A & $\mathrm{P}$ & $\mathrm{P}^{\mathrm{c}}$ & & & & & & & \\
\hline
\end{tabular}

os venenos botrópicos não produziram necrose, provavelmente devido a sua difusão por extensa região.

Novaes et al. (1986), com base em 42 experimentos realizados em bovinos para verificar o comportamento de um anti-inflamatório no tratamento do edema produzido no envenenamento por diversas espécies de Bothrops, descreveram o aspecto das lesões no local da picada (na face) ou da injeção de veneno (na bochecha, via subcutânea). Os autores relataram que, tanto nos bovinos tratados como nos testemunhas, se formou, momentos depois da picada ou da inoculação do veneno, um edema que se difundia pela face, queixo, barbela e peito. Este edema atingia o grau máximo, em média, às 48 horas pós-inoculação, podendo perdurar por 120 horas ou mais. Em todos os casos, o edema produzido por picada foi menor que o produzido por inoculação. Os edemas mais intensos foram provocados pelas espécies $B$. jararacussu, B. alternatus, B. atrox e B. moojeni, e os menos intensos por B. jararaca e $B$. neuwiedi. Os autores observaram que os traumatismos sofridos pelos animais no tronco de contenção deram origem a grandes hematomas. À necropsia verificou-se extenso edema sero-hemorrágico subcutâneo, que se estendia do local da inoculação (face), ao queixo, barbela e parte do tórax. À abertura da cavidade abdominal havia petéquias e sufusões subserosas no intestino grosso e rúmen. Hemorragias intestinais foram encontradas apenas em um animal, que apresentou as mucosas anêmicas. Na cavidade torácica, as lesões se limitavam a petéquias no coração e pericárdio (sic) e, por vezes, à presença de líquido sero-hemorrágico na cavidade pericárdica. Não foram fornecidos dados sobre alterações histológicas. Nos animais que morreram, inoculados ou por picada, a evolução oscilou entre 24 e 72 horas.

Em dois bovinos inoculados com veneno de Bothrops alternatus por via intramuscular superficial, Oliveira et al. (2004a) descreveram como lesões histológicas, necrose intensa e difusa, associada a infiltrado inflamatório neutrofílico na musculatura do membro anterior inoculado, nos linfonodos cervicais superficiais, do lado do músculo do membro que sofreu a inoculação, hiperplasia reacional dos folículos linfoides, parede da vesícula biliar intensamente hemorrágica e edematosa, com proliferação linfoide na submucosa; baço com acentuada congestão e hiperplasia de folículos linfoides. Em um bovino havia ainda infiltrado inflamatório neutrofílico, associado a hemorragia intensa e fibrina no epicárdio, e no miocárdio, congestão, hemorragia e infiltrado neutrofílico perivascular.

Em cinco vacas inoculadas (via não especificada) com o mesmo veneno, Oliveira et al. (2004b) constataram alterações do perfil sanguíneo caracterizadas por leucocitose, anemia normocítica normocrômica e redução de proteínas totais.

\section{Dados da nossa equipe referentes a bovinos}

Caldas et al. (2008) administraram o veneno de Bothrops alternatus a cinco bovinos por via subcutânea nas doses de $0,0625,0,125$ e $0,25 \mathrm{mg} / \mathrm{kg}$, e a dois outros por via intramuscular nas doses de 0,25 e $0,45 \mathrm{mg} / \mathrm{kg}$. Seis bovinos morreram (a evolução variou de 7h18min a 66h12min), e um que recebeu a menor dose (a de $0,0625 \mathrm{mg} / \mathrm{kg}$ ), por via subcutânea, recuperou-se (evolução de 92 horas). 0 quadro clínico, independentemente das doses, caracterizou-se por aumento de volume (hemorragia/hematoma) no local da inoculação, tempo de sangramento aumentado, mucosas hipocoradas e apatia. Os exames laboratoriais revelaram progressiva anemia normocítica normocrômica, trombocitopenia, redução de fibrinogênio e proteínas plasmáticas totais, hematócrito e hemoglobina diminuídos, além de leve aumento dos níveis de creatinaquinase e desidrogena- 
se lática. À necropsia, havia, a partir do local da inoculação, extensos hematomas e áreas de hemorragia no tecido subcutâneo dos animais que receberam o veneno por via subcutânea; nos animais inoculados por via intramuscular, adicionalmente, havia hemorragia intramuscular. 0 endocárdio esquerdo apresentava extensas hemorragias e verificaram-se petéquias na serosa do rúmen e do omaso, e na mucosa do abomaso e da vesícula biliar. Em cinco animais, o cólon, reto e região perirrenal estavam envoltos por coágulos de sangue. Ao exame histológico observou-se, além do quadro hemorragíparo, necrose muscular coagulativa, acompanhada de hemorragia, no entorno do local da inoculação nos animais que receberam o veneno por via intramuscular; essa lesão era discreta nos músculos próximos ao local de inoculação subcutânea. Nos bovinos deste estudo, o aumento de volume observado no local de inoculação e adjacências era constituído por sangue e não por edema. Não foram observadas mioglobinúria, nem lesões macro ou microscópicas significativas nos rins. Um bovino, após mostrar sinais clínicos moderados, recuperou-se em cerca de quatro dias.

\section{Dados da literatura referentes a ovinos}

Araujo \& Belluomini (1960/1962) verificaram que todos os venenos de Bothrops (B. jararaca, B. jararacussu, $B$. alternatus, B. cotiara, B. neuwiedi, B. atrox), produziram nos ovinos, edema no membro injetado (intramuscular). Não houve formação de necrose.

\section{Dados da nossa equipe referentes a ovinos}

Aragão et al. (2010), ao administrar o veneno de Bothropoides jararaca a dois ovinos, nas doses de 1,0 e $0,5 \mathrm{mg} / \mathrm{kg}$, e o de Bothrops jararacussu a dois outros ovinos, nas doses de 1,6 e $0,8 \mathrm{mg} / \mathrm{kg}$, sempre por via subcutânea, verificaram que três ovinos morreram, e um que recebeu a dose de $0,5 \mathrm{mg} / \mathrm{kg}$ do veneno de $B$. jararaca, recuperou-se. Os sinais clínicos tiveram início entre $7 \mathrm{~min}$ e $1 \mathrm{~h}$. 0 período de evolução variou de $7 \mathrm{~h} 9 \mathrm{~min}$ a $21 \mathrm{~h} 59 \mathrm{~min}$ nos animais que morreram. 0 quadro clínico, independentemente das doses, caracterizou-se por aumento de volume no local da inoculação, tempo de sangramento e de preenchimento capilar aumentados, taquicardia, dispneia, mucosas hipocoradas e apatia. Os exames laboratoriais revelaram acentuada anemia normocítica normocrômica, trombocitopenia, acentuada redução de fibrinogênio e de proteínas plasmáticas totais, hematócrito diminuído em dois animais, além de acentuado aumento de creatinaquinase e desidrogenase lática em todos os animais. À necropsia, os principais achados no local da inoculação e tecidos adjacentes eram extensas hemorragias, no animal que recebeu o veneno de $B$. jararaca. Nos dois animais envenenados por B. jararacussu havia edema no local da inoculação e acentuado edema pulmonar agudo. Além de hemorragia e edema, a principal alteração histológica verificada foi necrose das fibras musculares e de vasos, no local da inoculação e adjacências. Foi verificada necrose tubular renal, que foi atribuída ao quadro de choque.

No animal que não morreu, e que recebeu o veneno de B. jararaca, 32 horas após a inoculação a tumefação começou a diminuir e após 13 dias regrediu completamente.
Diefenbach et al. (2012), administraram o veneno de B. moojeni em dois ovinos, por via subcutânea, na face direita, nas doses de $0,41 \mathrm{mg} / \mathrm{kg}$ e $0,82 \mathrm{mg} / \mathrm{kg}$; a dois outros ovinos administraram o veneno de $B$. neuwiedi na dose de $1,0 \mathrm{mg} / \mathrm{kg}$. Verificaram que apenas o ovino que recebeu a menor dose $(0,41 \mathrm{mg} / \mathrm{kg})$ do veneno de B. moojeni sobreviveu, apesar de ter desenvolvido quadro clínico muito severo e semelhante aos demais. Os sinais clínicos iniciaram-se em cerca de 10 min após a inoculação em todos os ovinos. 0 período de evolução variou de 2 a 4 dias nos animais que morreram. 0 quadro clínico nos quatro ovinos caracterizou-se por apatia, acentuado aumento de volume da face, da porção ventral do pescoço e do peito, leve aumento de volume da porção proximal dos membros anteriores, tempo de sangramento aumentado, taquicardia, mucosas pálidas e grande quantidade de sangue não digerido nas fezes. Os exames laboratoriais revelaram, principalmente, redução das proteínas plasmáticas e aumento de creatinaquinase em todos os ovinos. À necropsia, foram observados extensos hematomas nas áreas correspondentes ao aumento de volume subcutâneo. Observaram-se petéquias, equimoses e sufusões leves a moderadas na serosa de diversos órgãos e acúmulo de sangue em meio às fezes na porção final do reto. Além de hemorragias, a principal alteração histológica observada foi necrose das fibras musculares esqueléticas e da parede de vasos, nas áreas próximas à inoculação do veneno. Um animal que recebeu o veneno de B. moojeni, 5 dias após o início do experimento apresentou regressão dos sinais clínicos e recuperou-se.

\section{Dados da literatura referentes a equinos}

Nos experimentos de Araujo \& Belluomini (1960-62), todos os venenos de Bothrops (vide acima as espécies) produziram edema no local da inoculação (intramuscular). Não houve formação de necrose em nenhum cavalo.

\section{Dados da nossa equipe referentes a equinos}

Sousa et al. (2011) administraram os venenos de Bothropoides jararaca, Bothrops jararacussu, Bothrops moojeni e Bothropoides neuwiedi, por via subcutânea a seis equinos, nas doses de 0,5 e $1 \mathrm{mg} / \mathrm{kg}$ (B. jararaca), 0,8 e $1,6 \mathrm{mg} / \mathrm{kg}$ (B. jararacussu), 0,205 (B. moojeni) e $1 \mathrm{mg} / \mathrm{kg}$ (B. neuwiedi). Os sinais clínicos iniciaram-se entre 8min e 2h10min após a inoculação. 0 período de evolução variou, nos quatro casos de êxito letal, de $24 \mathrm{~h} 41 \mathrm{~min}$ a $70 \mathrm{~h} 41 \mathrm{~min}$, e nos dois equinos que se recuperaram (os dois que receberam o veneno de $B$. jararacussu) foi de 16 dias. 0 quadro clínico, independente do tipo de veneno e das doses, caracterizou-se por aumento de volume no local da inoculação, arrastar da pinça do membro inoculado no solo, inquietação, apatia, diminuição da resposta aos estímulos externos, mucosas pálidas e hemorragias. Os exames laboratoriais revelaram anemia normocítica normocrômica com progressiva diminuição no número de hemácias, da hemoglobina e do hematócrito, e leucocitose por neutrofilia. Houve aumento de alamina aminotransferase, creatinaquinase, deshidrogenase lática, ureia e glicose, bem como aumento do tempo de ativação da protrombina e do tempo de tromboplastina parcial ativada. Os achados de necrop- 
sia foram extensas hemorragias no tecido subcutâneo, com presença de sangue não coagulado, em boa parte associado a edema (edema hemorrágico), que se estendia desde o local da inoculação até as regiões cervical, torácica, escapular e membro. Na periferia das áreas hemorrágicas observou-se edema gelatinoso. Nas cavidades torácica, pericárdica e abdominal havia grande quantidade de líquido sanguinolento. Não foram encontradas alterações histológicas significativas. Nos dois equinos inoculados com o veneno de $B$. jararacussu, a extensa tumefação diminuiu gradativamente e restou uma área flutuante com alopecia, que fistulou; por esta fístula escoava um líquido seroso amarelado. A lesão posteriormente cicatrizou.

\section{Dados da literatura referentes a suínos}

Araujo et al. (1963b), verificaram, em experimentos com porcos que receberam, pela via intramuscular os venenos de $B$. jararaca, $B$. jararacussu, B. alternatus, $B$. cotia$r a$, B. neuwiedi e B. atrox, que houve formação de grande edema. Pela via subcutânea (tecido adiposo) os venenos botrópicos produziram edema somente com o uso de doses superiors a $1 \mathrm{mg} / \mathrm{kg}$. Pela via intramuscular foi constatada a formação de necrose nas doses superiores a $1 \mathrm{mg} / \mathrm{kg}$ dos seguintes venenos botrópicos: B. jararacussu, B. neuwiedi e B. alternatus. Os outros venenos botrópicos (B. jarara$c a, B$. cotiara e $B$. atrox) não produziram necrose. Pela via subcutânea (tecido adiposo) todos os venenos botrópicos usados produziram necrose apenas com doses superiores a $1 \mathrm{mg} / \mathrm{kg}$.

\section{Quadro clínico-patológico do envenenamento natural botrópico em animais de produção}

\section{Dados da literatura referentes a bovinos}

Grunert (1967) e Grunert \& Grunert (1969) informaram que, no período de 1964-1966, deram entrada no Hospital de Clínica Veterinária da Universidade Federal do Rio Grande do Sul, em Porto Alegre, quatro vacas com lesões características de envenenamento botrópico. 0 principal sinal clínico observado foi um considerável aumento de volume, de consistência macia, no local da picada. Se a picada era na cabeça, havia dispneia e inquietação, se nos membros, verificou-se andar claudicante. Em casos graves havia hemorragias pela boca e pelas narinas, as fezes eram aquosas e hemorrágicas e as mucosas anêmicas. Até o $3^{\circ}$ dia, a tumefação aumentou pouco a pouco e a partir do $5^{\circ}$ dia diminuiu gradativamente. Devido às alterações necróticas no local da picada, havia cheiro pútrido a partir do $2^{\underline{0}}$ e $3^{\circ}$ dias. Na maioria dos casos, o estado geral estava bem alterado; os animais tinham andar cambaleante, inapetência, e estavam apáticos e gemiam. Observaram-se aumento das frequências cardíaca e respiratória, as conjuntivas e as mucosas estavam congestas. Só uma vaca recebeu, por via endovenosa, soro antiofídico, 6 horas após o acidente, porém teve o mesmo quadro clínico que os outros animais, que não receberam soro antiofídico. Apenas uma dessas vacas, gravemente afetada, morreu, com hemorragias pelas narinas, boca e reto, 12 horas após a entrada no Hospital, apesar de tratamento intensivo. A necropsia desta vaca revelou, além de edema e hemorragias do tecido subcutâneo no local da picada, graves hemorragias nas cavidades corporais e no trato digestivo. No coração e nas mucosas da cavidade bucal, do estômago (sic), do intestino e dos órgãos urinários e sexuais havia alterações hiperêmico-hemorrágicas. Não foi fornecida descrição das alterações histológicas.

De acordo com Menezes (1995/96), em sete casos naturais de envenenamento botrópico, diagnosticados na Clínica de Bovinos da Escola de Medicina Veterinária da Universidade Federal da Bahia, nos anos de 1985-1995, a sintomatologia caracterizou-se por apatia, súbito edema no local, dor, aumento de volume dos linfonodos regionais, hipertermia, anorexia, taquicardia, polipneia e dispneia mista, claudicação, além de necrose no local da picada, diminuição da coagulabilidade sanguínea e aborto. Os achados de necropsia verificados no único bovino que morreu (bezerra com um dia de idade) foram acentuado edema e grande área de necrose no local da picada (região perineal e vulva), da qual fluía líquido serossanguinolento, hemorragias retal e vaginal, petéquias nos linfonodos superficiais, no epicárdio, na mucosa intestinal e da bexiga, congestão dos pulmões e incoagulabilidade do sangue. Não foram fornecidas descrições das alterações histológicas.

\section{Dados da literatura referentes a ovinos}

Mendez \& Riet-Correa (1995) relataram picadas de cobra por Bothrops neuwiedi em ovinos numa fazenda no Rio Grande do Sul. Entre setembro 1988 e janeiro 1989 em um rebanho de 133 ovinos, 22 foram picados e 11 morreram. (Em um grupo de cinco caprinos na mesma fazenda, um foi picado e morreu.) Os ovinos, quando picados na cabeça, mostraram edema acentuado da cabeça, pescoço e, às vezes, na região do peito. Quando picados nos membros, mancavam acentuadamente e o edema às vezes se estendia até o abdômen ou tórax. As mortes, mais comuns em cordeiros e animais jovens, ocorreram dentro de 24 a 48 horas após a picada. A maioria dos animais adultos se recuperou. Necrose e desprendimento das partes superiores da pele foram observados em algumas ovelhas sobreviventes.

Barros (2008) forneceu os seguintes dados a respeito de um ovino, fêmea, com 18 meses de idade, procedente de Santa Maria, RS, em que foi concluído tratar-se de acidente ofídico por Bothrops. 0 animal foi encontrado no campo com edema acentuado na face, sangramento nasal e ocular bilateral e duas lesões perfurantes na face com distância de $2 \mathrm{~cm}$ ente elas. Os achados de necropsia consistiram em pele da face friável e hemorrágica, e tecido subcutâneo da face acentuadamente edematoso e hemorrágico; a hemorragia se estendia até a porção ventral do pescoço à altura da entrada do tórax e havia hemorragias no epicárdio e endocárdio. Histologicamente foram verificadas no miocárdio áreas multifocais a coalescentes de hemorragia, com moderado edema que separava as fibras musculares.

Aires et al. (2008) relataram a morte de dois ovinos, num mesmo pasto, numa fazenda da região central do Rio Grande do Sul, uma em setembro, outra em novembro de 2007, em que estabeleceram como causa acidente ofídico por Bothrops alternatus. Clinicamente observaram edema 
na face. À necropsia (os ovinos morreram no mesmo dia em que foram verificados os edemas na face) em ambos foi constatado, na pele e no tecido subcutâneo da face, edema e hemorragia, além de hemorragias em outros tecidos e órgãos. No exame microscópico de um dos dois ovinos, verificaram-se hemorragias em diversos tecidos e órgãos.

Gava \& Traverso (2008) estabeleceram o diagnóstico de morte por acidente ofídico (Bothops sp.) nos municípios de Lages e Campo Bello, SC, em dois ovinos, em que constataram, à necropsia, extensas hemorragias subcutâneas.

\section{Dados da nossa equipe referentes a ovinos}

Tokarnia et al. (2008) relataram a ocorrência de um acidente ofídico em um rebanho de ovinos, mestiços da raça Bergamascia, no município de Miguel Pereira, RJ. Quatro ovelhas adultas, com cerca de $35 \mathrm{~kg}$, foram picadas na cabeça por um exemplar de Bothrops jararaca dentro de curto espaço de tempo. Os animais apresentaram a cabeça muito tumefeita, mas o estado geral era bom. Em um ovino eutanasiado, verificou-se, à necropsia, que a tumefação da cabeça era causada por hemorragia subcutânea, e que se estendia ao pescoço. Histologicamente foi verificada, na face, hemorragia massiva, principalmente no tecido subcutâneo, com infiltração de hemácias no tecido muscular adjacente, que em áreas onde era mais intensa, provocou afastamento entre as fibras musculares, algumas com aspecto hialinizado. Em um exame das três ovelhas 4 dias após as picadas, verificou-se que estavam normais e que a tumefação da cabeça tinha desaparecido completamente. 0 tratador informou que no $3^{\circ}$ dia após as picadas, as cabeças das ovelhas só estavam um pouco "inchadas", e que no $4^{\circ}$ dia a lesão tinha desaparecido completamente, sem administração de qualquer medicamento.

\section{Dados da literatura referentes a equinos}

No Rio Grande do Sul, Raposo et al. (2000/2001) relataram um acidente ofídico em um equino de 1 mês de idade, que foi picado na orelha, em outubro de 1997; houve formação de edema, que, decorridas 24 horas após a picada, se estendia para o peito, membros anteriores e porção anterior do abdômen. Observaram ainda urina sanguinolenta, fezes com sangue e hemorragia na orelha picada. À necrop-

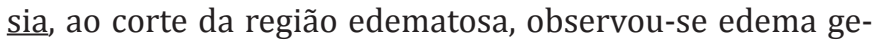
latinoso amarelo misturado com sangue vermelho escuro. Foram observadas petéquias e sufusões em diversos tecidos e órgãos, e hemorragias no tecido muscular próximas à área da picada. Os rins estavam aumentados e congestos e havia edema cerebral. Histologicamente foram observadas congestão e hemorragia severa na musculatura e em outros órgãos, áreas de necrose na musculatura próxima à área da picada e no baço, e no rim, necrose tubular aguda, congestão e hemorragia.

Barros (2003) forneceu os seguintes dados a respeito de um equino, em que foi concluído tratar-se de acidente ofídico por Bothrops. Tratava-se de uma fêmea, com 3 anos de idade, procedente de São Sepé, RS, que apresentou edema unilateral no focinho e na cabeça. Caminhava com os membros posteriores "travados", apresentava incoordenação, debatia-se e acabou morrendo com cerca de 12 horas de evolução do quadro clínico. À necropsia foram verificados hemorragia e edema difuso acentuados no tecido subcutâneo da cabeça e do pescoço, hemorragias interfasciculares acentuadas nos músculos esqueléticos e ainda hemorragias em diversos tecidos e órgãos. Histologicamente verificou-se no rim grande quantidade de cilindros intratubulares que preencheram a maioria dos túbulos tanto no córtex como na medula. Havia ainda hemorragia peritubular e periglomerular multifocal moderada.

\section{Descrições gerais}

Os dados do quadro clínico-patológico que chamamos de descrições gerais, baseados, em sua maioria, em envenenamento no homem e em experimentos realizados em animais de laboratório, constam nos textos de Amaral \& Rezende (1994), Azevedo-Marques et al. (2003), Barraviera (1994, 1999), Barravieira \& Pereira (1994), Borges (1999), França \& Málaque (2003) e Málaque \& França (2003), e resumimos da seguinte maneira:

\section{Ação dos venenos ofídicos, e quadros clínico-patológicos observados no homem e em animais de laboratório}

Segundo sua ação tóxica principal, os venenos das serpentes podem ser divididos em três grupos:

Veneno crotálico (as espécies de Crotalus sul-americanas), que possui como componente principal uma neurotoxina; Habermehl (1977) chama a atenção para o fato de que, no caso dos acidentes com a sul-americana Crotalus durissus terrificus não ocorrem as lesões locais observadas nos casos de envenenamento por cascavéis norte-americanas.

Veneno botrópico (Bothrops, Vipera, Lachesis e as espécies de Crotalus da América Central e do Norte), que causa forte lesão local (edema, hemorragia, necrose).

Veneno elapídico, que causa quase exclusivamente sintomas nervosos (Stöber 2002).

\section{Crotalus durissus terrificus}

Ação neurotóxica. As frações neurotóxicas (fundamentalmente a crotoxina) do veneno crotálico produziriam efeitos tanto no sistema nervoso central, quanto no sistema nervoso periférico. A crotoxina induz à paralisia, semelhante à causada pelo curare, em todas as espécies animais estudadas. Sugere-se que as paralisias motora e respiratória no envenenamento crotálico sejam decorrentes do bloqueio da transmissão nervosa na junção neuromuscular, por ação da neurotoxina que inibe a liberação de acetilcolina na sinapse.

Ação miotóxica. Tem sido atribuída à crotoxina, e mesmo à crotamina, a capacidade de produzir lesões no tecido muscular esquelético, sistemicamente, em pontos distantes do local da picada; há rabdomiólise sistêmica, traduzida por necrose hialina das fibras musculares esqueléticas, com consequente mioglobinúria.

Ação coagulante. A ação coagulante, semelhante à da trombina, acaba determinando um consumo dos fatores da coagulação e, por fim, a "incoagulabilidade" sanguínea. Há 
queda dos níveis sanguíneos de fibrinogênio com prolongamento do tempo de coagulação, ausência de protrombina e deficiência parcial de tromboplastina, sem redução do número de plaquetas. Apesar das alterações nos testes de coagulação, as manifestações hemorrágicas são discretas.

Ação nefrotóxica. 0 veneno crotálico ocasionaria lesão tubular direta, mas admite-se ainda uma ação indireta pela mioglobinúria (obstrução tubular por cilindros de mioglobina e lesão dos túbulos pelo miopigmento). Outros fatores, correlatos ao choque (desidratação com elevação do hematócrito, hipotensão arterial, acidose metabólica e sequestro de líquidos para a musculatura esquelética), podem estar associados à rabdomiólise e contribuem para a instalação da lesão renal. Nos casos que evoluem para a insuficiência renal aguda (IRA), há oligúria e anúria.

Quadro patológico do envenenamento crotálico. A lesão renal é referida como necrose tubular aguda, mas também têm sido relatadas glomerulonefrite e nefrite intersticial agudas, degeneração hidrópica e presença de cilindros de mioglobina. Nos músculos encontra-se necrose hialina das fibras musculares esqueléticas. No fígado haveria degeneração hidrópica dos hepatócitos com localização centrolobular. As hemorragias seriam raras nos órgãos internos, porém ocorreriam com maior frequência no sistema nervoso central. As causas mais importantes da morte são a IRA e o choque (este último é menos frequente no acidente crotálico do que nos acidentes botrópico e laquético).

\section{Bothrops spp.}

Ação necrosante ou proteolítica. Decorre da ação citotóxica direta de frações proteolíticas do veneno. A esta ação atribuem-se, principalmente, as lesões locais como rubor, edema, vesículas e necrose; os efeitos vasculotóxico e coagulante também podem contribuir para a instalação dessas lesões.

Ação vasculotóxica (hemorrágica). Determina aumento de permeabilidade ou rompimento da membrana basal do endotélio vascular e consequentes edema e hemorragia. As hemorragias podem ser locais ou sistêmicas, afetando os pulmões e rins; às vezes são fatais, quando ocorrem no sistema nervoso central. Além do edema no local da picada, há hemorragias na gengiva, epistaxe, hematemese, hematúria, hemorragia digestiva alta, e, às vezes, até no bordo do leito ungueal.

Ação coagulante. Além de ativar o fibrinogênio, a fração coagulante da maioria dos venenos botrópicos tem capacidade de ativar o fator X e a protrombina. Quando ocorre a ativação do fator $X$, há também consumo dos fatores V, VII e de plaquetas, levando ao quadro de coagulação intravascular disseminada (CID), com formação de microtrombos na rede capilar, o que poderia contribuir para desencadear a IRA.

Outras ações. Os acidentes botrópicos podem ser acompanhados de choque, com ou sem causas definidas, entre elas, a hipovolemia por perda de sangue ou plasma no membro edemaciado, a ativação de substâncias hipotensoras, o edema pulmonar e a CID. A insuficiência renal, observada eventualmente em envenenamentos botrópicos, poderia instalar-se por ação direta ou secundária a com- plicações em que o choque está presente; além disto, se admite que a CID é capaz de provocar isquemia renal por obstrução da microcirculação. Outro mecanismo proposto para explicar as lesões é ainda espasmo dos vasos renais por liberação de substâncias vasoativas.

Quadro patológico no envenenamento botrópico. Amorim et al. (1951) descreveram, com base em experimentos realizados em coelhos e ratos, no local da injeção, forte hemorragia e edema com necrose de coagulação do tecido subcutâneo e dos músculos estriados subjacentes, hemorragias em vários órgãos internos e trombose hialina nos capilares em $60 \%$ dos casos, principalmente no pulmão (em $47 \%$ dos casos). Os autores chamam a atenção para o valor que poderia ter esta última lesão para o diagnóstico do envenenamento ofídico. No rim esses autores encontraram somente lesões hiperêmico-hemorrágicas. Por outro lado, Barraviera \& Pereira (1994) e França \& Malaque (2003) descreveram no rim necrose tubular aguda, necrose cortical renal, glomerulonefrite e nefrite intersticial. As causas da morte, em geral, são IRA e hemorragias incontroláveis, além do choque.

O veneno de Lachesis muta possui ações proteolítica (necrosante), coagulante e vasculotóxica; admite-se ainda uma ação neurotóxica.

As serpentes do gênero Micrurus produzem veneno que têm, principalmente, ação neurotóxica.

\section{DISCUSSÃO}

\section{Casos experimentais do envenenamento crotálico}

Em relação aos achados de Araujo \& Belluomini $1960 / 1962$, que realizaram experimentos em diversas espécies de animais de produção, com a aplicação do veneno crotálico por via intramuscular, há concordância com os achados encontrados por nossa equipe no que diz respeito à falta de tumefação no local de aplicação do veneno (experimentos realizados em bovinos por Graça et al. 2008). Exceção se faz em relação ao cavalo, em que Araujo \& Belluomini (1960-62) descrevem um pequeno edema, porém nossa equipe observou edema acentuado (Lopes et al 2012).

A ausência de qualquer reação no local da inoculação, em experimentos realizados por Araujo et al. (1963a) em bovinos, pela aplicação do veneno crotálico, por via subcutânea ou intramuscular, também está de acordo com as observações da nossa equipe (Graça et al. 2008).

Birgel et al. (1983) descreveram no envenenamento crotálico em bovinos microhematúria, que nossa equipe não observou (Graça et al. 2008), nem outros pesquisadores que realizaram experimentos em animais de produção.

Saliba et al. (1983) descreveram em bovinos, também no envenenamento crotálico, necrose hialina nas paredes das arteríolas no sistema nervoso central, no pulmão e no local da aplicação do veneno, e trombos hialinos na luz de arteríolas e capilares pulmonares, e no rim processos degenerativos, culminando em necrose tubular, e glomerulonefrite focal, alterações que nossa equipe não observou (Graça et al. 2008), nem outros estudiosos que realizaram experimentos em animais de produção.

Em relação às descrições gerais sobre o envenenamento crotálico há várias divergências: nossa equipe não 
observou mioglobinúria nem em bovinos (Graça et 2008), nem em equinos (Lopes et al. 2012) e também não observou necrose de túbulos uriníferos ou nefrite em bovinos (Graça et al. 2008) e em equinos (Lopes et al. 2012)

\section{Casos experimentais do envenenamento botrópico}

Em relação aos achados de Araujo \& Belluomini (1960/62) e Araujo et al. (1963a) que fizeram experimentos em várias espécies de animais de produção, com a aplicação do veneno de diversas espécies de Bothrops, por via intramuscular e subcutânea, há concordância com os achados de nossa equipe à respeito da ocorrência de tumefação (que esses autores interpretam como edema) no local de aplicação do veneno em todas as espécies (em nossos experimentos em bovinos (Caldas et al, 2008), ovinos (Aragão et al. 2010, Diefenbach et al. 2012) e equinos (Sousa et al, 2011). Esses autores interpretam esta tumefação como um edema, o que esta em desacordo com os nossos achados, com raras exceções. Mais detalhes sobre a natureza desta tumefação vide abaixo.

Novaes et al. (1986), no envenenamento por diversas espécies de Bothrops em bovinos, induzidos por picadas na cara e também pela inoculação de veneno dessecado na bochecha, verificaram, que "edemas" mais intensos foram provocados pelas espécies $B$. jararacussu, $B$. alternatus, $B$. atrox e B. moojeni; os "edemas" de menor intensidade foram observados com as espécies B. jararaca e B. neuwiedi. Porém nos achados de necropsia, Novaes et al. (1986) falam em edema sero-hemorrágico.

Em relação à tumefação, nos experimentos realizados por nossa equipe em bovinos com o veneno de B. alternatus, a acentuada tumefação era devido a hematoma (Caldas et al. 2008).

Nos experimentos realizados por nossa equipe em ovinos com os venenos de B. jararaca, B. moojeni e B. neuwiedi, a tumefação no local da aplicação (subcutânea) era devido a extensas hemorragias (Aragão et al. 2010, Diefenbach et al. 2012). Nos experimentos realizados por nossa equipe em equinos com os venenos de B. jararaca, $B$. moojeni e $B$. neuwiedi, a tumefação foi devido a extensas hemorragias no tecido subcutâneo, com presença de sangue não coagulado e em boa parte associadas a edema (edema hemorrágico) (Sousa et al. 2011).

Nos estudos realizados por nossa equipe o bovino que recebeu o veneno de B. alternatus (Caldas et al. 2008) e os ovinos que receberam os venenos de B. jararaca (Aragão et al. 2010) e de B. moojeni (Diefenbach et al. 2012), e que não morreram, a tumefação acentuada do sangue acumulado no tecido subcutâneo no local da inoculação (devido a hematoma) foi reabsorvida sem deixar sequelas.

Exceção foi a reação ao veneno de $B$. jararacussu: nos ovinos a tumefação era devida ao acentuado edema (Aragão et al. 2010); os dois ovinos que receberam o veneno de $B$. jararacussu morreram, de maneira que não foi possível verificar a evolução do quadro clínico e se haveria necrose. Nos dois equinos que receberam o veneno de $B$. jararacussu e que não morreram, após acentuada tumefação houve fistulação com eliminação de um líquido amarelado, que posteriormente cicatrizou; desta maneira não se ficou sabendo se a tumefação nesse caso era devida a edema ou a hemorragia (Sousa et al. 2011).

De acordo com Araujo \& Belluomini (1960-62) e Araujo et al. (1963a), necrose no local da inoculação só ocorreu quando os venenos botrópicos foram inoculados por via intramuscular; não podemos fazer comparações, pois com exceção da inoculação por via intramuscular do veneno de Bothrops alternatus em dois bovinos, que morreram de evolução aguda, todas as outras inoculações feitas por nossa equipe foram por via subcutânea (Caldas et al. 2008).

Em bovinos inoculados com veneno de B. alternatus, nossa equipe observou, ao exame histológico, necrose muscular coagulativa, acompanhada de hemorragia, somente no entorno do local da inoculação nos animais que receberam o veneno por via intramuscular; essa lesão era discreta nos músculos próximos ao local de inoculação subcutânea. (Caldas et al. 2008) Em ovinos, a nossa equipe verificou, após aplicação dos venenos botrópicos, por via subcutânea, somente necrose das fibras musculares e de vasos no local de inoculação e adjacências. (Aragão et al. 2010, Diefenbach et al. 2012)

Vital Brasil (1918) afirma que os venenos botrópicos $(B$. jararaca, B. alternatus e B. jararacussu) produzem em animais reações locais violentas e, quando o envenenamento é demorado, haveria formação de necrose.

Com relação às descrições gerais, nossa equipe observou nos rins de ovinos leves alterações degenerativas com evolução para lise, necrose de coagulação em alguns túbulos do córtex, presença de cilindros hialinos intratubulares, além de formação incipiente de microtrombos em alguns glomérulos e capilares. No fígado foram observadas alterações degenerativas e focos de necrose incipiente e indícios de atividade pró-coagultória (microtrombos granulares) e corpúsculos de choque granulares. A necrose tubular foi atribuída ao quadro de choque. (Aragão et al. 2010, Diefenbach et al. 2012)

\section{Casos naturais do envenenamento botrópico}

Nos dois casos, um em ovino, outro em equino, verificados em Santa Maria, a tumefação, de acordo com a descrição e as fotos fornecidas por Barros $(2003,2008)$, é de natureza sero-hemorrágica.

Na necropsia de uma ovelha picada por uma serpente do gênero Bothrops (Tokarnia et al. 2008) em que se observou hemorragia subcutânea massiva, não verificou-se necrose; nos exames histopatológicos foi vista discreta necrose de algumas fibras musculares nas adjacências do acúmulo do sangue no tecido subcutâneo.

Grunert (1967) e Grunert \& Grunert (1969) mencionaram necrose em seus casos naturais de envenenamento por Bothrops em bovinos.

Melo et al. (2004) inseriram em seu texto sobre "Envenenamento botrópico" fotografias de um bovino com necrose na face maxilo-mandibular, sem fornecer dados sobre a espécie de Bothrops envolvida.

Em relação a casos naturais de envenenamento ofídico também deve ser lembrado que quando a cobra pica o animal, junto com o veneno pode inocular germes patogênicos, responsáveis por necrose e processos infecciosos. 


\section{CONCLUSÕES}

Nos experimentos realizados por nossa equipe, a aplicação do veneno de Crotalus durissus terrificus em equinos, por via subcutânea, provocou edema acentuado no local da aplicação, ao contrário do que ocorreu nas outras espécies, aspecto não relatado na literatura. Ainda em relação ao veneno de Crotalus durissus terrificus, ao contrário do que está relatado na literatura, não se verificou hemoglobinúria em bovinos e equinos, e não se verificaram lesões renais nessas mesmas espécies.

Em relação ao veneno de Bothrops, nos experimentos realizados por nossa equipe, por injeção subcutânea do veneno no bovino, ovino e equino, a tumefação era devido à hemorragia, e não devido a edema, como relatado na literatura. Nos casos em que os animais se recuperaram, esta foi rápida, pela reabsorção do sangue, sem deixar sequelas. Somente o veneno de B. jararacussu causou nos ovinos edema subcutâneo na região da aplicação do veneno. Como os animais morreram, não foi possível verificar se eventualmente haveria evolução para necrose. Nos equinos a natureza da tumefação causada pelo veneno de $B$. jararacussu não pode ser averiguada, pois os animais não morreram; porém ao contrário do que foi observado em relação aos venenos das outras espécies de Bothrops (em bovinos e ovinos), não houve reabsorção do conteúdo da tumefação, e sim fistulação.

Nos únicos experimentos realizados por nossa equipe, em que o veneno botrópico (B. alternatus) foi inoculado em dois bovinos por via intramuscular - de acordo com a literatura a única via que causa necrose - necrose somente foi comprovada, histologicamente, em fibras musculares no entorno do local da inoculação.

Ao contrário do relatado na literatura, sobre envenenamento botrópico, (a) em relação às lesões renais nos ovinos, somente foram verificadas, nos experimentos realizados pela nossa equipe, alterações leves, que foram atribuídas ao quadro de choque, (b) nos bovinos que receberam o veneno de $B$. alternatus, não foram verificadas lesões renais, (c) nos equinos que receberam o veneno de Bothrops spp., não foram encontradas alterações histológicas significativas, inclusive no rim, (d) não houve hemoglobinúria ou mioglobinúria, em bovinos, ovinos e equinos.

As diferenças sobre a ocorrência de edema/hemorragias e necrose no envenenamento botrópico tem, como se pode ver pelo acima exposto, como causa (a) variação da ação do veneno de acordo com a espécie da serpente envolvida, (b) variação na reação das diversas espécies animais aos venenos das cobras, (c) variação da reação de acordo com a profundidade da aplicação do veneno (subcutâneo ou intramuscular), (d) variação da composição do veneno na mesma espécie de cobra de acordo com sexo, idade, alimentação, ambiente, clima, (e) divergências nas interpretações; (f) deve se acrescentar que frequentemente a palavra edema é usada como sinônimo de tumefação (inchaço), independentemente da causa, (g) e que a inoculação de patógenos junto com o veneno pode influenciar a natureza da lesão.

\section{REFERÊNCIAS}

Aires R.A., Marin J.B., Cecim M.S. \& Leal M.L.R. 2008. Acidente ofídico em ovinos da região central do Rio Grande do Sul. 35 Conbravet, 19-22 out., Gramado, RS.

Amaral C.F.S. \& Rezende N.A. 1994. Tratamento das complicações dos acidentes por animais peçonhentos, p.345-372. In: Barraviera B. (Ed.), Venenos Animais: uma visão integrada. EPUC, Rio de Janeiro.

Amorim M.F., Mello R.F. \& Saliba F. 1951. Envenenamento botrópico e crotálico. Mem. Inst. Butantan 23:63-108.

Aragão A.P., Tokarnia C.H., Graça F.A.S., França T.N., Coelho C.D., Caldas S.A. \& Peixoto P.V. 2010. Envenenamento experimental por Bothropoides jararaca e Bothrops jararacussu em ovinos: aspectos clínico-patológicos e laboratoriais. Pesq. Vet. Bras. 30(9):717-728.

Araujo P. \& Belluomini H.E. 1960/62. Toxicidade de venenos ofídicos. I. Sensibilidade específica de animais domésticos e de laboratório. Mem. Inst. Butantan 30:143-156.

Araujo P., Rosenfeld G. \& Belluomini H.E. 1963a. Toxicidade de venenos ofídicos. II. Doses mortais para bovinos. Arqs Inst. Biológico, São Paulo, 30:43-48.

Araujo P., Rosenfeld G., Rosa R.R. \& Belluomini H.E. 1963b. Toxicidade de venenos ofídicos. III. Resistência dos porcos aos venenos ofídicos. Arqs Inst. Biológico, São Paulo, 30:49-56.

Azevedo-Marques M.M., Hering S.E. \& Cupo P. 2003. Acidente crotálico, p.91-98. In: Cardoso J.L.C., França F.O.S., Wen F.H., Málaque C.M.S. \& Haddad Jr V. (Eds), Animais Peçonhentos no Brasil: biologia, clínica e terapêutica dos acidentes. Sarvier, São Paulo.

Barbosa J.D., Sousa M.G.S., Tokarnia C.H., Brito M.F., Belo-Reis A.S., Bomjardim H.A., Lopes C.T.A. \& Oliveira C.M.C. 2011. Quadro clínico-patológico do envenenamento crotálico experimental em bubalinos comparado com o de bovinos. Pesq. Vet. Bras. 31(11):967-973.

Barraviera B. 1994. Acidentes por serpentes dos gêneros Crotalus e Micrurus, p.281-295. In: Barraviera B. (Ed.), Venenos Animais: uma visão integrada. EPUC, Rio de Janeiro.

Barraviera B. 1999. Ofídios, Estudo Clínico dos Acidentes. Editora de Publicações Biomédicas, Petrópolis. 46p.

Barraviera B. \& Pereira P.C.M. 1994. Acidentes por serpentes do gênero Bothrops, p.261-280. In: Barraviera B. (Ed.), Venenos Animais: uma visão integrada. EPUC, Rio de Janeiro.

Barros C.S.L. 2003. Comunicação pessoal (Departamento de Patologia, Universidade Federal de Santa Maria, RS).

Barros C.S.L. 2008. Comunicação pessoal (Departamento de Patologia, Universidade Federal de Santa Maria, RS).

Belluomini H.E., Araujo P., Rosenfeld G., Leinz F.F. \& Birgel E.H. 1982. Symptomatologie der experimentellen Crotalustoxin-Vergiftung bei Rindern, die einer spezifischen Serumtherapie unterworfen wurden. Dtsch. Tierärztl. Wochenschr. 89(11):444-448.

Birgel E.H., Belluomini H.E. \& Leinz F.F. 1983. Auswertung der Urinbefunde bei Rindern mit experimenteller Crotalus-Vergiftung. Zbl. Vet. Med. A 30:283-289.

Borges R.C. 1999. Serpentes Peçonhentas Brasileiras: manual de identificação, prevenção e procedimentos em caso de acidentes. Atheneu, São Paulo.

Caldas S.A., Tokarnia C.H., França T.N., Brito M.F., Graça F.A., Coelho C.D. \& Peixoto P.V. 2008. Aspectos clínico-patológicos e laboratoriais do envenenamento experimental por Bothrops alternatus em bovinos. Pesq. Vet. Bras. 28(6):303-312.

Diefenbach A., Anjos B.L., Caldas S.A., Peixoto T.C., Brito M.F., Yamasaki E.M., Rita P.H.S. \& Tokarnia C.H. 2012. Aspectos clinicopatológicos e laboratoriais do envenenamento experimental por Bothrops moojeni e Bothropoides neuwiedi em ovinos. Pesq. Vet. Bras. 12(1):49-60.

França F.O.S. \& Málaque C.M.S. 2003. Acidente botrópico, p.72-86. In: Cardoso J.L.C., França F.O.S., Wen F.H., Málaque C.M.S. \& Haddad Jr V. (Eds), Animais Peçonhentos no Brasil: biologia, clínica e terapêutica dos acidentes. Sarvier, São Paulo. 
Gava A. \& Traverso S.D. 2008. Comunicação pessoal (Departamento de Clínica e Patologia, Centro de Ciências Agroveterinárias, Universidade do Estado de Santa Catarina, Lages, SC).

Graça F.A.S., Peixoto P.V., Coelho C.D., Caldas S.A. \& Tokarnia C.H. 2008. Aspectos clínicos e patológicos do envenenamento crotálico experimental em bovinos. Pesq. Vet. Bras. 28(6):261-270.

Grunert E. 1967. Beobachtungen über Schlangenbissverletzungen bei grossen Haustieren in Süd-Brasilien. Dtsch. Tierärztl. Wochenschr. 74(20):531-532.

Grunert E. \& Grunert D. 1969. Beobachtungen von Bothrops-Schlangenbissverletzungen bei Rind und Pferd in Rio Grande do Sul/Brasilien. Veterinär-Medizinische Nachrichten Heft 3, p.217-232.

Habermehl G. 1977. Gift-Tiere und ihre Waffen. 2.Aufl. Springer-Verlag, Berlin.

Lago L.A. 1996. Avaliação clínica e laboratorial de bovinos submetidos ao envenenamento crotálico experimental (Crotalus durissus terrificus Laurenti, 1768), Crotamina positivo. Dissertação de Mestrado, Universidade Federal de Minas Gerais, Escola de Veterinária, Belo Horizonte. 62p.

Lopes C.T.A., Tokarnia C.H., Brito M.F., Sousa M.G.S., Oliveira C.M.C., Silva N.S., Lima D.H.S. \& Barbosa J.D. 2012. Aspectos clínico-patológicos e laboratoriais do envenenamento crotálico experimental em equinos. Pesq. Vet. Bras. 32(9):843-849.

Málaque C.M.S.A. \& França F.O.S. 2003. Acidente laquético, p.87-90. In: Cardoso J.L.C., França F.O.S., Wen F.H., Málque C.M.S \& Haddad Jr V. (Eds), Animais Peçonhentos no Brasil: biologia, clínica e terapêutica dos acidentes ofídicos. Sarvier, São Paulo.

Melo M.M., Silva Jr P.G.P., Lago L.A., Verçosa Jr D. \& Habermehl G.G. 2004. Envenenamento botrópico, p.59-79. In: Araújo R.B., Oliveira M.M.V. \& Nunes I.J. (Eds), Serpentes Venenosas. Cad. Téc. Vet. Zootec. 44, FEPMVZ Editora, Belo Horizonte.

Mendez M.C. \& Riet-Correa F. 1995. Snakebite in sheep. Vet. Human Toxicol. 37(1):62-63.
Menezes R.V. 1995/96. Ofidismo em bovinos. Arq. Esc. Med. Vet. Bahia 18(1):224-231.

Novaes A.P., Lucas S., Abe A.S., Fernandes W., Puorto G. \& Almeida I.L. 1986. Envenenamento botrópico em bovinos: tratamento opcional. Circ. Téc. no.3, Embrapa-UEPAE, São Carlos, SP. 29p.

Oliveira N.J.F., Melo M.M., Ribeiro E.L., Lago L.A. \& Lucia M. 2004a. Achados histopatológicos em bovinos experimentalmente envenenados com veneno de Bothrops alternatus. $31^{\circ}$ Conbravet, São Luiz, MA. (Resumo)

Oliveira N.J.F., Ribeiro E.L., Silva J.P.G.P., Lago L.A., Lucia M. \& Melo M.M. 2004b. Bovine blood profile after Bothrops alternatus envenomation. $8^{\circ}$ Congresso da Sociedade Brasileira de Toxinologia, Angra dos Reis, RJ. (Resumo)

Raposo J.B., Méndez M.C., Baialardi C.E.G. \& Raffi M.B. 2000/01. Acidente ofídico em equino no Brasil: relato de caso. Revta Fac. Zootec. Vet. Agron., Uruguaiana, 7/8(1):5-8.

Saliba A.M., Belluomini H.E. \& Leinz F.F. 1983. Experimentelle Crotalus-Vergiftung bei Rindern: Anatomisch-pathologische Studie. Dtsch. Tierärztl. Wochnschr. 90:513-517.

Sousa M.G., Tokarnia C.H., Brito M.F., Reis A.B., Oliveira C.M., Freitas N.F., Oliveira C.H. \& Barbosa J.D. 2011. Aspectos clinico-patológicos do envenenamento botrópico experimental em equinos. Pesq. Vet. Bras. 31(9):773-780.

Stöber M. 2002. Giftschlangenbiss, p.1276-1278. In: Dirksen G., Gründer H.-D. \& Stöber M. (Eds), Innere Medizin und Chirurgie de Rindes. 4. Aufl. Parey-Verlag, Berlin.

Tokarnia C.H., Brito M.F., Malafaia P. \& Peixoto P.V. 2008. Acidente ofídico em ovinos causado por Bothrops jararaca. Pesq. Vet. Bras. 28(12):643648.

Vital Brasil 1918. Do envenenamento ofídico e seu tratamento: coletânea de trabalhos 1901-1917. Instituto Butantã, São Paulo. Tipografia do "Diário Oficial", 31-55. (Apud Araujo \& Belluomini 1960/62) 